\title{
A New Evaluation Method for the Fracability of a Shale Reservoir Based on the Structural Properties
}

\author{
Haoyue Sui $\mathbb{D}^{1,2,3}$ Wei Gao $\mathbb{D}^{1,2}$ and Ruilin $\mathrm{Hu} \mathbb{D}^{1,2,3}$ \\ ${ }^{1}$ Key Laboratory of Shale Gas and Geoengineering, Institute of Geology and Geophysics, Chinese Academy of Sciences, \\ Beijing 100029, China \\ ${ }^{2}$ Institutions of Earth Science, Chinese Academy of Sciences, Beijing 100029, China \\ ${ }^{3}$ University of Chinese Academy of Sciences, Beijing 100049, China
}

Correspondence should be addressed to Wei Gao; gaowei@mail.iggcas.ac.cn

Received 17 April 2019; Revised 24 June 2019; Accepted 22 November 2019; Published 4 December 2019

Academic Editor: Lionel Esteban

Copyright (c) 2019 Haoyue Sui et al. This is an open access article distributed under the Creative Commons Attribution License, which permits unrestricted use, distribution, and reproduction in any medium, provided the original work is properly cited.

\begin{abstract}
The fracability of shale reservoirs is one of the key indicators used for evaluating whether or not the shale can be used as a "sweet spot zone." It has been determined that the structural properties of rock have important influences on the evaluation of the fracability of reservoirs. In the current study, five rock quality designation (RQD) calculation methods were compared and analyzed for the purpose of selecting an $\mathrm{RQD}_{\mathrm{I}}$ for characterizing rock structures. Focused on the lack of structural factors included in the previous fracability evaluation methods, a new model for fracability evaluation based on the combination of the brittleness index, structural index, and fracture toughness was constructed using a linear elastic fracture theory. The model showed that good fracability not only included higher brittleness but also required less energy to produce cracks. Meanwhile, good fracability also required more discontinuous structural planes. In the current study, a formation with a higher fracability index was considered to be a fractureable interval and a formation with a lower fracability index was a fracture barrier. Finally, the reservoir fracability index was modeled using the Xike 2 well in the north of Guizhou Province as a case study. Subsequently, a fracability logging evaluation method based on the fracability index model was determined, which will potentially provide a new technical tool for future fracturing optimization processes.
\end{abstract}

\section{Introduction}

As an important strategic resource in China, the exploration and development of shale gas (oil) have significant impacts on China's energy and economy. The shale reservoirs are dense, with very low matrix porosity and permeability, as well as poor natural productivity. The traditional mining methods have not been found to be applicable in shale reservoirs. Therefore, the majority of shale gas wells require "hydraulic fracturing" and other stimulation measures in order to improve the production results. It has become very necessary to carry out scientific shale reservoir fracability evaluation in order to obtain better reservoir cracking effects and avoid blind fracturing.

In recent years, researchers have utilized the brittleness of rock in order to evaluate reservoir fracability and screen superior hydraulic fracturing horizons [1-5]. It has been found that brittleness is one of the most important rock mechanics properties $[6,7]$. It is generally assumed that formations with high brittleness are more susceptible to fractures. However, this assumption has not been constantly established in different types of strata. Daniel et al. and Bai pointed out that some reservoirs are not easy to fracture, despite the fact that their brittleness indexes are high $[8,9]$. For example, limestone dolomite is known to have higher brittleness. However, when compared with shale, the energy required to produce cracks is higher, the fracturing gradients are larger, and cracks cannot be generated under the same pressure $[2,5,10-12]$. Therefore, it was concluded that as a single factor, rock brittleness cannot accurately and objectively reflect the fracturing properties of reservoirs. Subsequently, Enderlin et al. used material brittleness and toughness for the characterization process [13]. In another study, Tang et al., Yuan et al., and Guo et al. applied multiple 
factors, such as comprehensive brittleness indexes, fracture toughness, and mechanical parameters and hardness of rock to evaluate the fracability of reservoirs [14-16]. However, the majority of the previous studies did not quantitatively consider the effects on the fracability of the structural characteristics of the rock $[17,18]$. Zhu et al. proposed a new shale fracability evaluation method based on the laboratory test, coupling brittleness, stress-strain data, and fracture morphology [19]. It is believed that the key to a successful reservoir reformation is the formation of a maximized seam spread. However, natural fractured formations are known to be prone to form complex fracture networks after fracturing occurs [20]. There are three types of expansion modes which occur after hydraulic cracks encounter natural cracks: passing, diverting, and passing plus diverting [21-24]. Therefore, the existence of discontinuous bodies, such as structural planes, generally will lead to the expansion of hydraulic fracturing cracks, as well as change of morphology. These factors tend to have major impacts on fracture fracability. In brief, the more complex the rock structures for hydraulic fracturing, the more the structural planes of the fracture-induced cracks will connect and penetrate, which can potentially produce complex fracture networks $[25,26]$. Therefore, rock structures are important indicators which can be used to evaluate the fracability potentials of reservoirs.

In summary, the evaluations of fracability should consider not only the brittleness of the rock but also the amount of energy required to combine the cracks and the structural properties of the rock. Therefore, this study examined the following aspects: (1) The quantitative characterization of the rock structures which had been obtained by RQD was analyzed and compared using various RQD definitions, and a selection was made of the optimal RQD representation method for characterizing the complexity of the rock structures. (2) Consideration was given to the brittleness index, fracture toughness, and structure index $\left(\mathrm{RQD}_{\mathrm{I}}\right)$ in order to establish a shale reservoir fracability evaluation model. (3) The proposed model was applied to the fracability evaluation of the Longmaxi Formation-Wufeng Formation shale section of the Xike 2 well in northern Guizhou. Geological interpretations were used to verify the results, and the dominant fracturing section was preferentially selected.

\section{Study Area}

The study area is located in the Qianbei Depression on the southwestern edge of the Yangtze area and is zoned north to the Sichuan Basin. The region to the west is the Zhaotong Depression, and the southern part is adjacent to the Qianzhong paleohigh [27]. A map of the study area is shown in Figure 1. The Wufeng Formation-Longmaxi Formation is continuously deposited, and this is the target interval of this study.

The Wufeng Formation is mainly composed of black carbonaceous mud shale, which is about $3.3 \mathrm{~m}$ thick, and contains a large amount of pyrite and graptolite (Figure 2). The horizontal bedding is developed in the interval, reflecting the fact that the water is relatively quiet during the deposi- tion. The sedimentary environment of this section is a deep water shelf. The Longmaxi Formation is divided into the upper and lower sections: the lower section is mainly shale and mudstone with a thickness of $45.7 \mathrm{~m}$, which is developed by pyrite laminae and is categorized as a deep water shelf, while the upper stratum is interbedded shale, sandy mudstone, and limestone, with a thickness of $56.9 \mathrm{~m}$, and is a shallow shelf facies. The bore histogram of the Xike 2 well is shown in Figure 3.

In the present study, X-ray diffraction analyses of 128 samples were conducted in the Xike 2 well of the WufengLongmaxi Formation. It was observed that the shale mainly contained quartz, feldspar, calcite, illite, pyrite, and other minerals, as shown in Figure 4. Also, the minerals could mainly be divided into three categories: clay minerals, quartz-feldspar-pyrite, and carbonates. The ternary diagram of the mineral composition is shown in Figure 5. The following results were obtained from the analysis of the two figures: (1) The brittle minerals were mainly quartz, potassium feldspar, plagioclase, calcite, dolomite, iron dolomite, and pyrite. The content levels were found to be high (between $46.4 \%$ and $90.7 \%$ ), with an average of approximately $69.9 \%$, which gradually increased with depth. The highest values were found to occur between 370 and $390 \mathrm{~m}$. (2) The clay minerals were mainly composed of illite and illite-smectite mixed layers, which had gradually decreased with the increases in depth in the longitudinal direction. The volume fraction ranged between $8.9 \%$ and $51.5 \%$, with an average of approximately $28.3 \%$. (3) The proportion of silicate rock minerals is relatively large in brittle minerals, with an average content of $54.6 \%$, and the content levels of carbonate minerals and pyrite were approximately $12.5 \%$ and $3.2 \%$, respectively.

\section{Methodology}

\subsection{Influence Factors for the Fracability of the Shale}

3.1.1. Brittleness of the Rock. Rock brittleness is an intrinsic property and reflects the fact that there is no obvious absorption of mechanical energy in irreversible deformation prior to rock fractures. It has been observed that brittle shale is prone to form relatively complicated seam networks during fracturing, while plastic rock will become deformed and not be prone to produce seams. A brittleness index will characterize the instantaneous difficulties of the rock prior to failure, as well as reflecting the difficulties in forming seam networks after a reservoir has fractured. It has been found that the greater the brittleness index is, the more sensitive the reservoir will be to fracturing reactions and the greater the probability that a complex network will be formed. Zhu et al., Wang et al., and Li et al. summarized the existing calculation methods of the rock brittleness index [19, 29, 30]. Chinese and international researchers have derived more than 20 different brittleness indexes based on different theoretical bases. However, the most commonly used methods mainly include two types. The first type characterizes the brittleness based on the mineralogical compositions of the rock, while the second type uses the rock mechanics parameters for its characterization. 

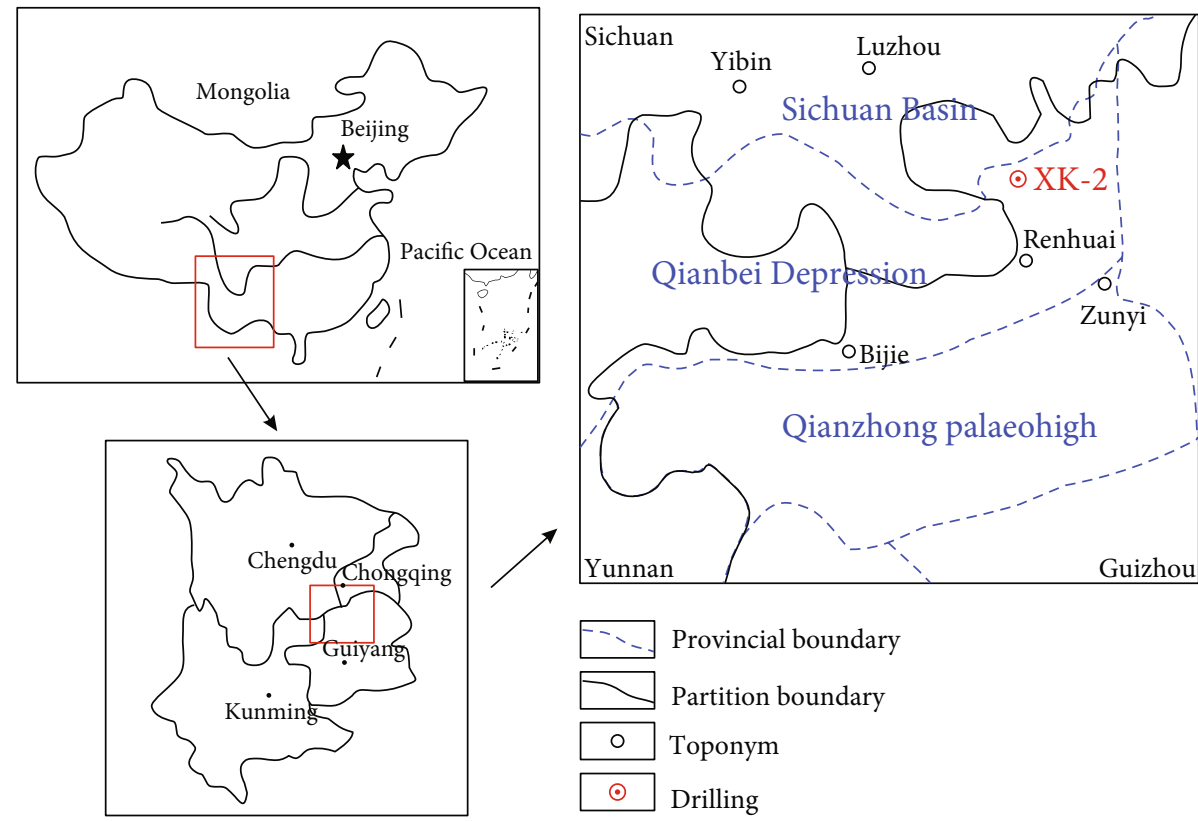

FIGURE 1: Location of the study area.

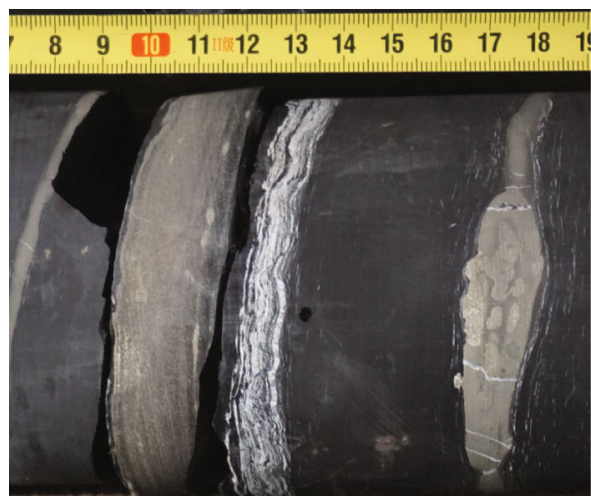

(a)

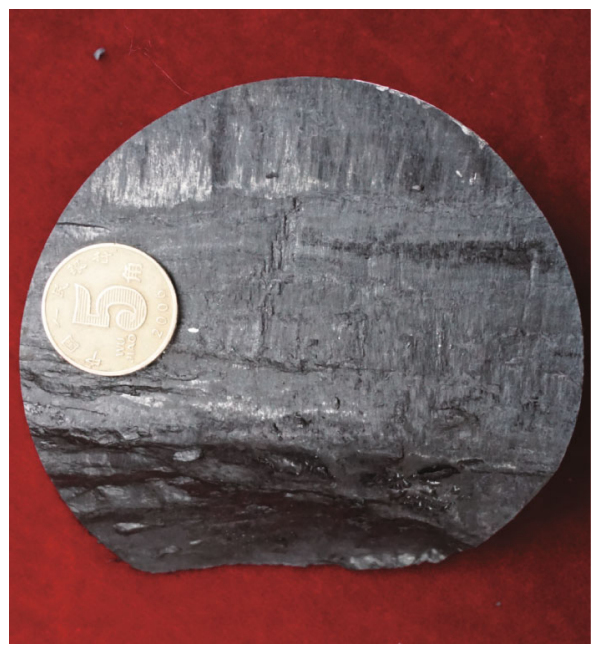

(c)

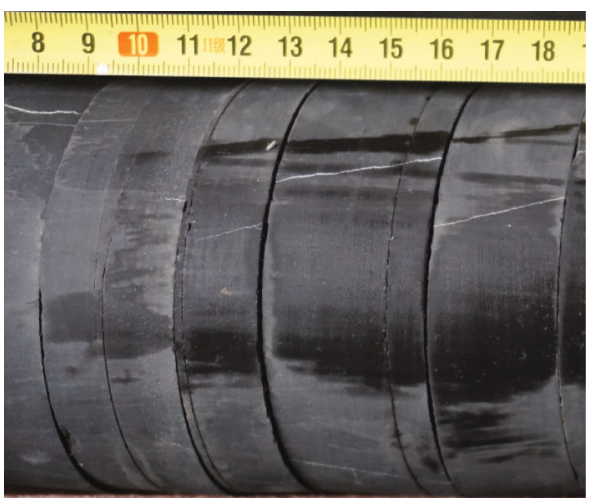

(b)

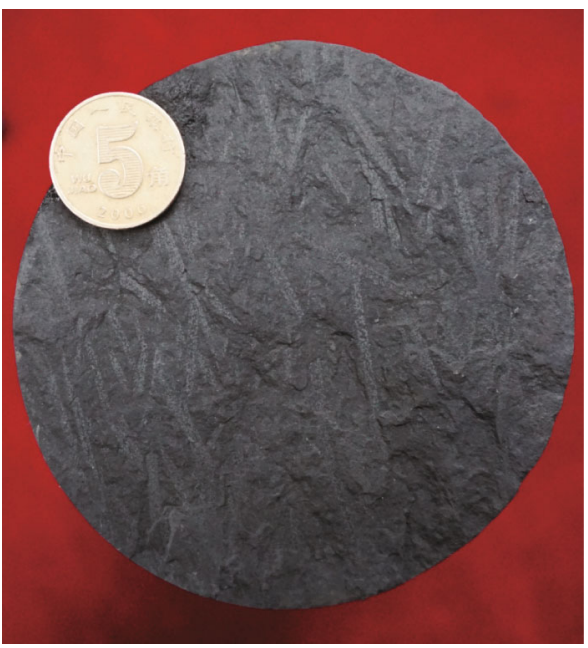

(d)

Figure 2: Photograph of the core: (a) pyrite; (b) horizontal bedding; (c) carbonaceous shale; (d) graptolite. 


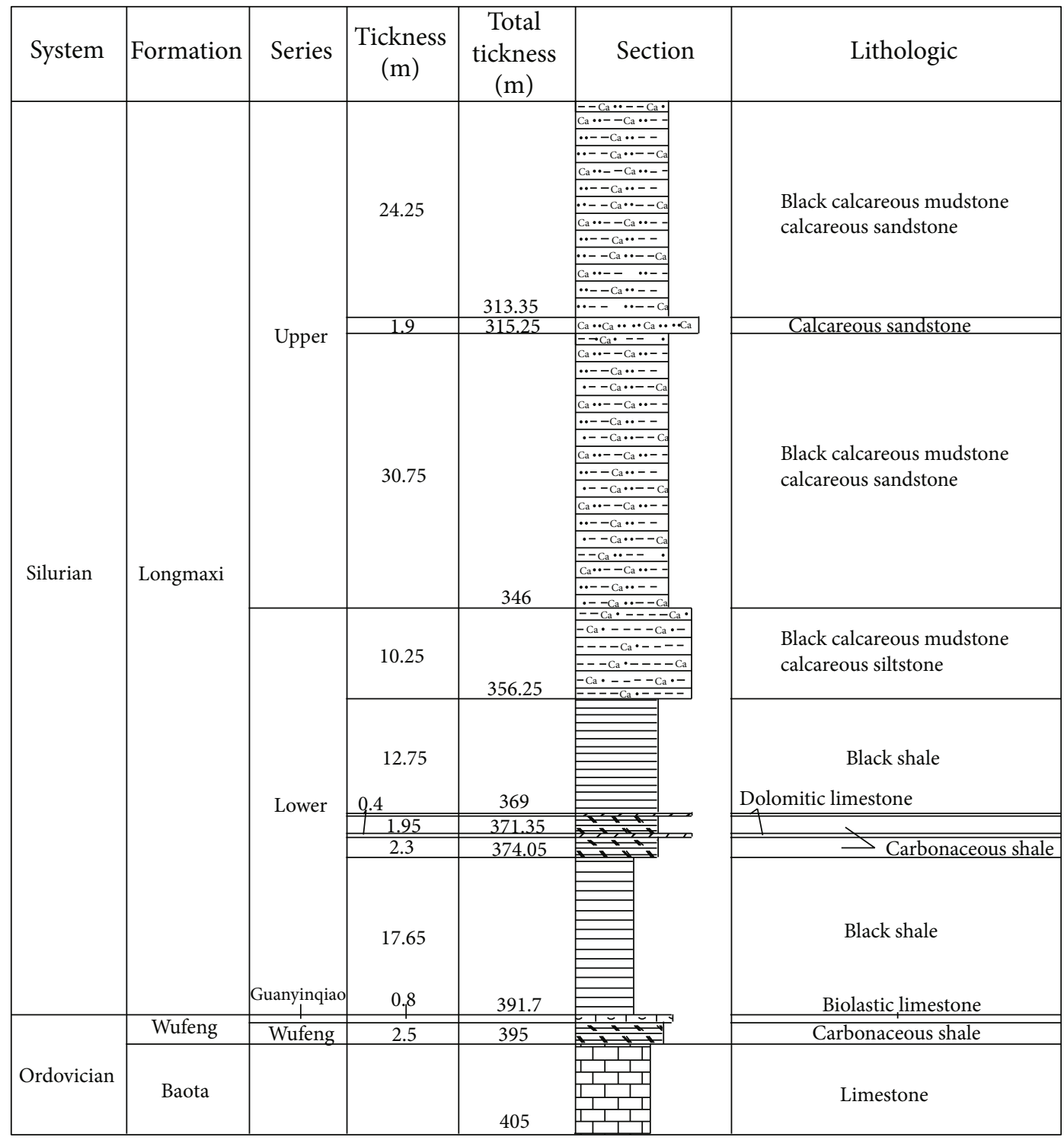

Figure 3: Stratigraphic histogram of the Wufeng-Longmaxi Formation (modified from Zhu et al. [28]).

(1) Mineral Component Evaluation Method. Carbonate minerals, clay minerals, and quartz are the main minerals found in shale gas reservoirs [31]. Silicate minerals, such as quartz, are known to exhibit brittleness. Meanwhile, clay minerals generally display high ductility. Previously, Jarvie et al. defined a rock brittleness index which was based on mineral components, which referred to the percentage of quartz minerals in the total mineral content [1]. More recently, many researchers have completed further examinations in order to optimize and add carbonate minerals, silicate minerals, and pyrite to the brittleness indexes of minerals as follows [32]:

$$
B_{1}=\frac{W_{\text {sil }}+W_{\text {carb }}+W_{\text {py }}}{W_{\text {tal }}},
$$

where $B_{1}$ is the mineral brittleness index, $W_{\text {sil }}, W_{\text {carb }}$, and $W_{\text {py }}$ are weights of silicate minerals, carbonate minerals, and pyrite, respectively, and $W_{\text {tal }}$ is the total mineral weight.
In the present study, Equation (1) was used to calculate the brittleness index in order to obtain the second curve, as shown in Figure 3. The rock brittleness index was observed to be high (between 0.6 and 0.9) and was found to be larger in the ranges of 310 to $315 \mathrm{~m}$ and 375 to $395 \mathrm{~m}$. It was found in this study that the method of characterizing rock brittleness using the percentages of brittle minerals in the rock as the brittleness index was simple and practical. However, the whole rock mineral analysis was mainly dependent on indoor XRD testing results and mineral logging data. It should be noted that the logging mineral content data were not obtained from the study area. In addition, the indoor XRD tests had major limitations due to the difficulties and costs related to the coring processes. Therefore, it was impossible to continuously measure the entire well in the study area for this experimental examination.

(2) Mechanical Parameter Method. The mechanical parameter method is mainly defined based on Young's modulus and 


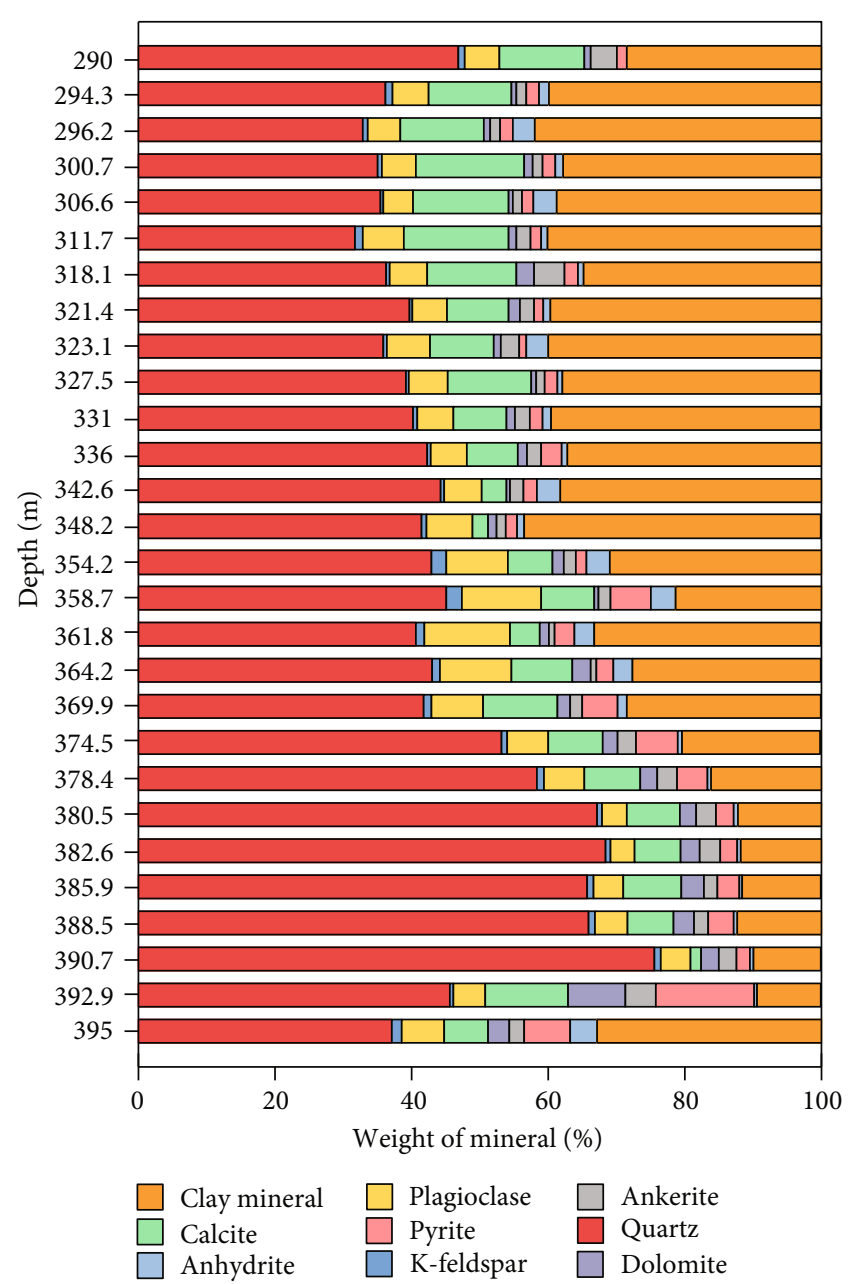

Figure 4: Bar chart of mineral proportions.

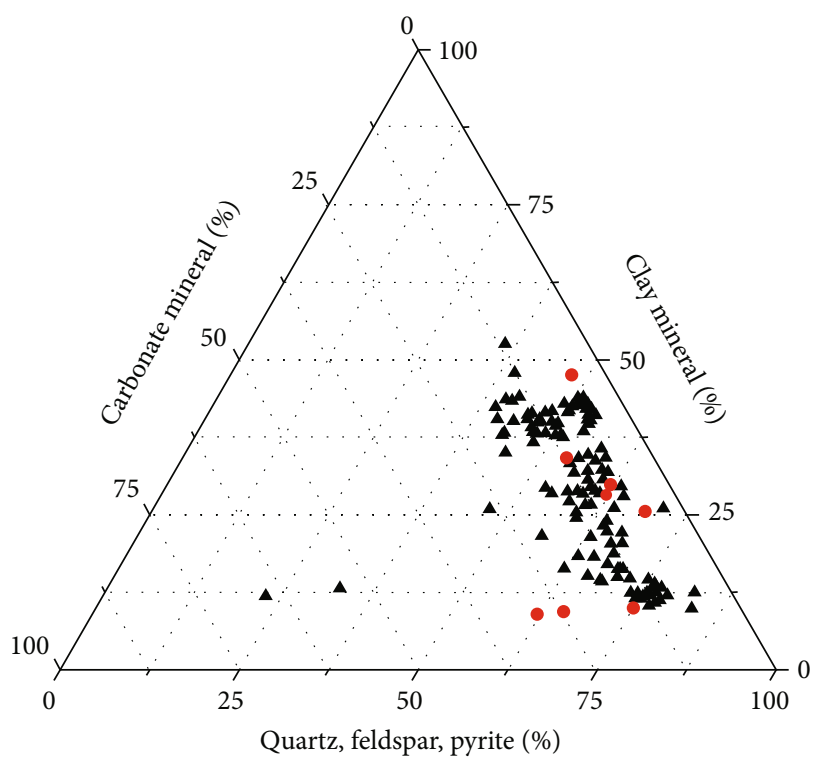

- Longmaxi formation

- Wufeng formation

FIGURE 5: Ternary diagram of mineral compositions.
Poisson's ratio. Young's modulus reflects the ability to maintain cracks after rock ruptures, and Poisson's ratio indicates the ability of rock to resist cracking under pressure. Therefore, it is known that the larger Young's modulus is, the smaller Poisson's ratio will be. Furthermore, the brittleness of the rock will be stronger and more prone to the formation of complex seam networks. In previous studies, Rickman et al. analyzed the shale data in the Barnett region of North America and established the following brittleness index calculation formula based on the elastic mechanics parameters [2]:

$$
B_{2}=\frac{E_{\mathrm{n}}+v_{\mathrm{n}}}{2}
$$

where $E_{\mathrm{n}}$ and $v_{\mathrm{n}}$ are the normalized Young's modulus and Poisson's ratio, respectively, which can be defined as follows:

$$
\begin{gathered}
E_{\mathrm{n}}=\frac{E-E_{\min }}{E_{\max }-E_{\min }}, \\
v_{\mathrm{n}}=\frac{v_{\max }-v}{v_{\max }-v_{\min }} .
\end{gathered}
$$

In the equation, $E_{\max }$ and $E_{\min }$ represent the maximum and minimum static Young's modulus of the study interval, denoted as $\mathrm{GPa}$, and $v_{\max }$ and $v_{\min }$ indicate the maximum and minimum static Poisson's ratio of the study interval.

Logging curve interpretations are the most cost-effective method for rock brittleness evaluations. This is due to the continuity of the logging data and the high-resolution characteristics of the data. Therefore, based on the abovementioned mechanical parameter method, this study used an acoustic wave and density logging method to calculate the brittleness index of the entire well which was examined in the study area. The calculation results were compared with the rock brittleness index after the XRD tests for analysis purposes. The prepared brittleness index profile of the Xike 2 well in the Wufeng-Longmaxi Formation is detailed in Figure 6 as follows: (1) In the Xike 2 well of the WufengLongmaxi Formation, Young's modulus of the regional shale ranged from 15 to $80 \mathrm{GPa}$ and Poisson's ratio changed only minimally in the range of 0.25 to 0.35 . (2) The strata with high Young's modulus and low Poisson's ratio were determined to have the highest brittleness index, as indicated in lines 3 and 4 of Figure 6. (3) The brittleness index of the rock ore was parallel with the brittleness index of the rock mechanics in the comparison results. Although the two were not identical, the curve change tendency was determined to have a high degree of coincidence, as detailed in line 5 of Figure 6. Moreover, it was found that the two brittleness calculation methods could be successfully applied in northern Guizhou.

3.1.2. Fracture Toughness. Fracture toughness is an important factor which is used to characterize the difficulties of reservoir reformations and reflects the ability of cracks to maintain forward extensions during fracturing processes. It has been observed that during the hydraulic fracturing processes of shale reservoirs, the induced fractures are mainly type I and type II fractures. Therefore, based on Irwin's 


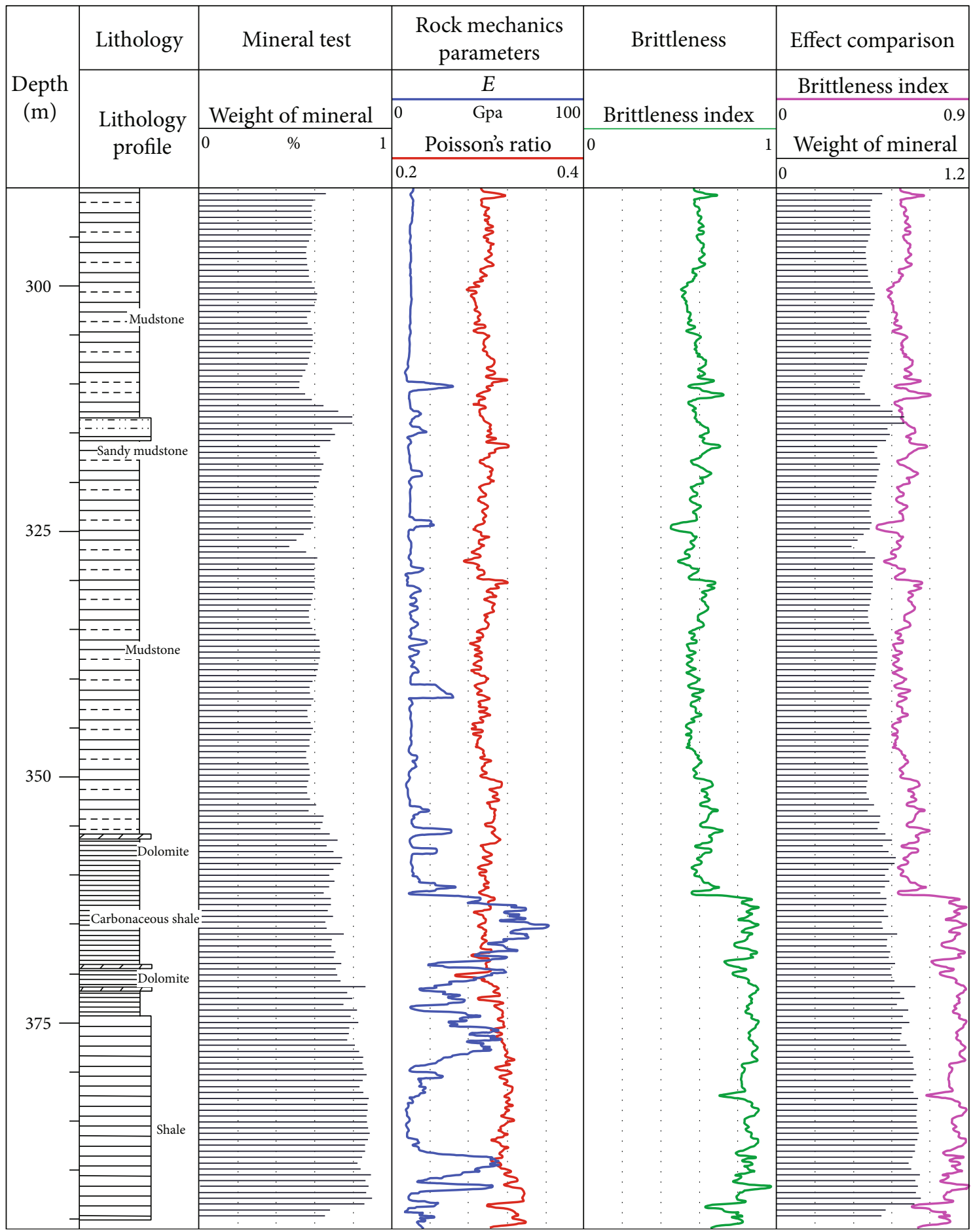

FIGURE 6: Comparison of different brittleness indexes for Xike 2.

theory of fracture mechanics, when the stress intensity factor $K_{\mathrm{J}}$ at the crack tips reaches the critical value $K_{\mathrm{IC}}$, the cracks will begin to become destabilized and expand. For example, $K_{\text {IC }}$ is the fracture toughness of the rock, which indicates the rock's resistance to brittle fractures as a property of the rock itself. Therefore, the magnitude of the fracture toughness reflects the difficulty of the crack propagation. It has been determined that the larger the fracture toughness value is, the more difficult it will be for cracks to become extended. In contrast, the greater the crack-forming abilities of the hydraulic fracturing processes, the more prone to expansion the cracks will be, which will be beneficial to the generation of hydraulic fracture networks.

Previously, based on a large number of experimental data, Chen et al., Jin and Chen, and Jin et al. established an equivalent calculation method between the fracture 
toughness, confining pressure $\sigma_{n}$, and uniaxial tensile strength $S_{\mathrm{t}}$ of type I and type II cracks. The formula is as follows [33-35]:

$$
\begin{aligned}
K_{\mathrm{Ic}} & =0.2176 \sigma_{n}+0.0059 S_{\mathrm{t}}^{3}+0.0923 S_{\mathrm{t}}^{2}+0.517 S_{\mathrm{t}}-0.3322, \\
K_{\mathrm{IIc}} & =0.0956 \sigma_{n}+0.1383 S_{\mathrm{t}}-0.082
\end{aligned}
$$

where $K_{\mathrm{Ic}}$ and $K_{\mathrm{IIc}}$ are type I and type II fracture toughness, in which $\mathrm{Mpa} \cdot \sqrt{m} ; \sigma_{n}$ is the confining pressure (MPa); and $S_{\mathrm{t}}$ denotes the uniaxial tensile strength $(\mathrm{MPa})$. The rock mechanical parameters involved in the formula were obtained from logging data and empirical formulas commonly used in petroleum engineering [36]:

$$
\begin{aligned}
I_{\mathrm{GR}} & =\frac{\mathrm{GR}-\mathrm{GR}_{\min }}{\mathrm{GR}_{\max }-\mathrm{GR}_{\min }}, \\
V_{\mathrm{cl}} & =\frac{2^{I_{\mathrm{GR}} G_{\mathrm{cur}}}-1}{2^{G_{\mathrm{cur}}}-1}, \\
\sigma_{n} & =\left(0.0045+0.0035 V_{\mathrm{cl}}\right) E_{\mathrm{d}}, \\
S_{\mathrm{t}} & =\frac{\sigma_{n}}{K},
\end{aligned}
$$

where $I_{\mathrm{GR}}$ is the shale content index (dimensionless); $\mathrm{GR}_{\min }$ and $\mathrm{GR}_{\max }$ represent the minimum and maximum of the gamma value (API); $V_{\mathrm{cl}}$ denotes the shale content (\%); $G_{\text {cur }}$ indicates the Hilchie index, which is related to the stratigraphic age and is taken as 2 for the old stratum; $E_{\mathrm{d}}$ is the dynamic elastic modulus (GPa); and $K$ indicates a constant, with the value of 12.26 .

3.1.3. Structural Characteristics. The structural characteristics of rock have significant influences on the physical properties of reservoirs. It has been found that the existence of horizontal bedding tends to lead to the permeability in the lateral direction of reservoirs being significantly stronger than those in the longitudinal direction, and the diffusion abilities of the shale gas will decrease in the vertical layer direction. Also, the massive existence of weak planes has been found to be beneficial to the expansion and development of fractured cracks.

For the standard characterization of rock integrity, the most commonly used method in engineering is the rock quality index (RQD) calculation. Many Chinese and international researchers have established empirical models using RQD in order to characterize the rock mechanical properties. At the present time, the application of RQD has rapidly expanded to other areas of rock mechanics. These have become one of the basic parameters of geotechnical engineering. Therefore, based on the abovementioned situation, a modified core RQD was used to characterize the structural properties of the rock in the study area, as well as to quantitatively represent the rock integrity. Then, the fracability of the rock reservoir in the study area was evaluated.

In one of the earliest related studies, D.U. Deere and D.W. Deere (USA) proposed a rock quality index (RQD) evaluation model based on a revised coring rate method in 1963 [37]. In the model, the percentage of the cumulative length of the core with a length $\geq 10 \mathrm{~cm}$ accounts for the footage in a drilling round trip:

$$
\mathrm{RQD}=\frac{\text { length of core pieces }>10 \mathrm{~cm}}{\text { total core run length }} \times 100 \text {. }
$$

However, it was not difficult to find many shortcomings in the above equation, such as the following: (1) The angle between the drilling direction and the structural surface is not considered. As a result, when the drilling direction is nearly parallel to the normal direction of the structural plane, the obtained RQD value will be significantly larger than the RQD value of the drilling direction perpendicular to the normal direction of the structural plane. (2) It is clearly unreasonable to evaluate the rock structure with a fixed length of $10 \mathrm{~cm}$ as the threshold value. For example, when the joint spacing is less than $10 \mathrm{~cm}$, the RQD is 0 , while when the spacing is greater than $10 \mathrm{~cm}$, the RQD is 100 . However, there is a significant difference in the integrity. As shown in Figure 7, the cores of segments $a$ and $b$ have equal RQD values, yet the structural plane $a$ is more complicated. (3) Due to the singularity of the drilling direction, the conventional RQD has no property with any direction, but only of directionality. Meanwhile, the rock structure surface has different directions. Therefore, the use of RQD to evaluate the rock structures will result in major errors.

Currently, based on the abovementioned deficiencies, Chinese and international researchers have conducted a great deal of studies. Subsequently, the traditional RQD has been revised, as shown in Table 1. In 1995, Palmstrom proposed the definition of weighted joint density (WJD), which has been used to obtain more information from the drilling surfaces, and its calculation methods and parameters are shown in Tables 1 and 2. Meanwhile, Palmstrom confirmed in 1996 that the WJD value is similar to the volume joint number $J_{v}$, which is used for RQD calculations, as detailed in rows 2 and 3 of Table 1 [39]. In 2006, Shirouyeh Araghi introduced a new method for calculating borehole RQD (MRQD) [38], which was based on the number of joints, karst, fracture zones, cavities, and strongly weathered rock formations, as shown in row 4 of Table 1 . In another related study, Li et al. proposed a definition of corrected RQD $\left(\mathrm{RQD}_{\mathrm{c}}\right)$ [40], which is believed to be not only dependent on the cumulative lengths of unbroken pieces but also controlled by the number of unbroken pieces, as illustrated in row 5 of Table 1. In 2015, Azimian proposed a rock structure evaluation method using $\mathrm{RQD}_{\mathrm{I}}$ values, as shown in row 6 of Table 1 [38]. The RQD mainly considers the joint-core angles and the core fractures. In the current research study, the RQD of the borehole core in the Xike 2 well was calculated using the abovementioned four methods, and the results are shown in Table 3.

In accordance with the method proposed by Deere, this study compared the various results of the RQD calculations shown in Table 3, and the RQD values were biased to the maximum or the minimum. It was found that when the number of cores with lengths between 3 and $10 \mathrm{~cm}$ was large, 


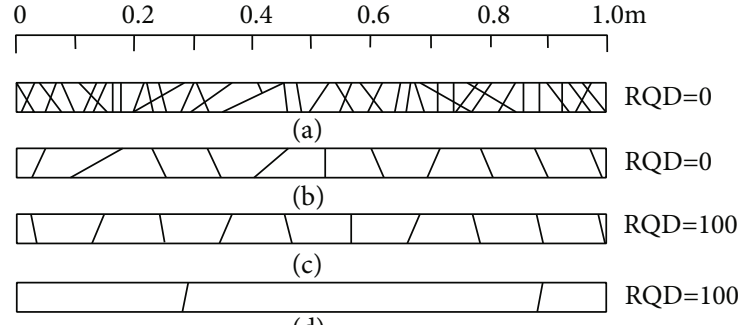

(d)

FIgURE 7: Examples of RQD values for various joint densities along drill cores [38].

the RQD value tended to be minimally biased. For example, for the 112th and 113th round trips, the number of 3 to $10 \mathrm{~cm}$ length cores was determined to be smaller in the 112 th round trip. However, there were $175.5 \mathrm{~cm}$ core voids and extreme fractured areas observed. During the 113th round trip, the core was relatively complete. However, the core lengths were shorter, and the number of cores measuring between 3 and $10 \mathrm{~cm}$ accounted for approximately $40 \%$. Therefore, the calculated RQD for the 112th group was greater than that of the 113th group, which was inconsistent with the actual situation (Figure 8). The RQD value obtained using the Palmstrom calculation method had not considered the weak areas of the rock and had ignored the parameters related to the weak areas. This had resulted in inconsistency with the actual situation. For example, for the 111th, 112th, $123 \mathrm{rd}$, and 132nd round trips, the rocks had displayed extremely broken sections with complex rock structures, and the RQD calculated according to the two formulas of Palmstrom was 100, which was not consistent with the actual in situ data. The calculation method of $\mathrm{RQD}_{\mathrm{c}}$ takes the number of rocks with unbroken lengths into consideration. However, this was not applicable to the current study since the RQD value was small and the fluctuations were not significant. It was found that the values obtained using the MRQD and RQD calculation methods were similar. This was determined to be mainly due to the fact that the core high-angle fractures in the Xike 2 well were less and were primarily broken along the joint plane. Therefore, since the $\mathrm{RQD}_{\mathrm{I}}$ method had considered the joint directions, such as in the 105th, 108 th, and 118th round trips, it was found to be more accurate for the descriptions of the core structures.

In the current study, the comparison results indicated that the $\mathrm{RQD}_{\mathrm{I}}$ values had better characterized the rock structures. The different core samples had displayed different quantitative indexes which had comprehensively considered multiple control factors, such as core erosion, fractures, and joint direction. This had provided more reliable and accurate evaluation values of the quality and structures of the rock. Meanwhile, this study obtained the statistical data of the core bedding line density. For example, the number of intersecting layers on the lengths of the unit surveying lines in the normal direction of the bedding surface was compared with the $\mathrm{RQD}_{\mathrm{I}}$ results. As can be seen from the bar graph shown in Figure 9, the $\mathrm{RQD}_{\mathrm{I}}$ had changed unevenly with depth during the different round trips. The positions at the well depths of $310 \mathrm{~m}, 320$ to $330 \mathrm{~m}, 340 \mathrm{~m}, 370 \mathrm{~m}$, and $390 \mathrm{~m}$, respectively, were observed to be relatively low. Also, at the well depths of 310 to $320 \mathrm{~m}, 330$ to $340 \mathrm{~m}, 360 \mathrm{~m}$, and 375 to $385 \mathrm{~m}$, respectively, the $\mathrm{RQD}_{\mathrm{I}}$ values were observed to be relatively high. It was found that when compared with the right line density bar chart, the change trend was generally the opposite. Therefore, when combined with the scatter chart (Figure 10), it was not difficult to see that the two had a good correlation. It has been determined that during engineering applications, $\mathrm{RQD}_{\mathrm{I}}$ can be effectively used for structural characterizations. This method has the advantages of simple operation, easy use, and high comprehensiveness, which are beneficial to promoting its application on project sites.

3.2. Comprehensive Evaluation Method for Fracability. The effects of shale reservoir reformations are dependent on the complexity of the fracture networks and the sizes of the obtained reservoir reformations. The complexities of fracture networks during their formations are closely related to the brittleness and structural characteristics of the formation rocks. When structural planes have been developed in the rock, the brittleness will be higher, and the fracture networks which are formed within the rock formations will be more complex. The sizes of the reservoir reformations are mainly dependent on the fracture toughness of the rock formations. For example, the smaller the fracture toughness value is, the stronger the seaming abilities of the rock during the hydraulic fracturing processes will be and the greater the probability of obtaining larger reservoir reforming volumes will be. Therefore, based on the aforementioned principles, the related research results presented by Jin et al. and Chen et al. were adopted to create a new model for fracability evaluations as follows [32, 33]:

$$
F_{i}=\frac{\alpha S_{n}+\beta B_{n}+\gamma K_{n}}{\alpha+\beta+\gamma},
$$

where $F_{i}$ represents the fracability index; $\alpha, \beta$, and $\gamma$ denote the effect contributions of the shale structure, brittleness, and fracture toughness on the fracability, respectively, in which $\alpha+\beta+\gamma=1$ was simplified to $\alpha=\beta=\gamma=1 / 3$ in the current study; and $S_{n}, B_{n}$, and $K_{n}$ represent the range-normalized $\mathrm{RQD}_{\mathrm{I}}$ value, brittleness index, and fracture toughness index, respectively. The specific algorithm is shown as follows [41]:

$$
\begin{aligned}
S_{n} & =\frac{\mathrm{RQD}_{\text {max }}-\mathrm{RQD}}{\mathrm{RQD}_{\text {max }}-\mathrm{RQD}_{\text {min }}}, \\
B_{n} & =\frac{B-B_{\text {min }}}{B_{\max }-B_{\min }}, \\
K_{n} & =\frac{K_{\mathrm{Icmax}}-K_{\mathrm{Ic}}}{2\left(K_{\mathrm{Icmax}}-K_{\mathrm{Icmin}}\right)}+\frac{K_{\mathrm{II} \max }-K_{\mathrm{IIc}}}{2\left(K_{\mathrm{IIcmax}}-K_{\mathrm{IIcmin}}\right)},
\end{aligned}
$$

where $\mathrm{RQD}_{\text {max }}$ and $\mathrm{RQD}_{\text {min }}$ are the maximum and minimum values of the rock quality index in the well section, respectively; $B_{\max }$ and $B_{\min }$ are the maximum and minimum values of the brittleness index in the study section, respectively; and $K_{\text {Icmax }}, K_{\text {Icmin }}, K_{\text {IIcmax }}$, and $K_{\text {IIcmin }}$ are the 
TABLE 1: Selected expressions of RQD.

\begin{tabular}{|c|c|c|}
\hline Reference & Formula & Variable declaration \\
\hline $\begin{array}{l}\text { Palmstrom } \\
{[39]}\end{array}$ & $\mathrm{RQD}=115-3.3 J_{v}(\mathrm{WJD})$ & \multirow{2}{*}{$\begin{array}{c}\text { WJD is the weighted joint density; WJD }=(1 / L) \sum f_{i}, f_{i}=1 / \sin \alpha, \\
\text { where } \alpha \text { is the angle between the joint and borehole; } J_{v} \text { is the } \\
\text { volumetric joint count }\end{array}$} \\
\hline $\begin{array}{l}\text { Palmstrom } \\
{[39]}\end{array}$ & $\mathrm{RQD}=110-2.5 J_{v}(\mathrm{WJD})$ & \\
\hline $\begin{array}{l}\text { Shirouyeh } \\
\text { Araghi [38] }\end{array}$ & $\mathrm{MRQD}=100-\frac{1.5 \mathrm{nd}+\mathrm{CW}+\mathrm{Fr}+\mathrm{Cr}+\mathrm{VZ}+C}{\text { total core run length }} \times 100$ & $\begin{array}{l}\text { nd is the number of discontinuities; } \mathrm{CW} \text { is the length of the core } \\
\text { washed segment; Fr is the length of the fragmented segment (with } \\
\text { spacing of } 15-50 \mathrm{~mm} \text { ); } \mathrm{Cr} \text { is the length of the crushed segment (with } \\
\text { spacing of 5-15 mm); VZ is the vuggy zone; } C \text { is the cavity or core loss }\end{array}$ \\
\hline Li et al. [40] & $\mathrm{RQD}_{\mathrm{c}}=\frac{P_{r}}{f(N)}$ & $\begin{array}{c}N \text { is the number of unbroken pieces; } P_{r} \text { is the ratio of recovered cores } \\
\text { in length: } P_{r}=\left(\sum_{i=1}^{N} L_{i}\right) / L \text {, where } L \text { is the travel or run length and } L_{i} \\
\text { is the length of } i \text { th unbroken piece; } f(N) \text { is the function of the total } \\
\text { number of unbroken pieces; } f(N)=N^{a} \text {, where } a \text { is the material } \\
\text { parameter }\end{array}$ \\
\hline $\begin{array}{l}\text { Azimian } \\
{[38]}\end{array}$ & $\mathrm{RQD}_{\mathrm{I}}=100-\frac{f_{i}+\mathrm{CW}+\mathrm{Fr}+\mathrm{Cr}+K}{\text { total core run length }} \times 100$ & $\begin{array}{c}f_{i} \text { is the rating factor obtained from Table } 2 ; \mathrm{CW} \text { is the length of the } \\
\text { core washed segment; Fr is the length of the fragmented segment } \\
\text { (with spacing of } 15-50 \mathrm{~cm} \text { ); Cr is the length of the crushed segment } \\
\text { (with spacing of }<15 \mathrm{~mm} \text { ); } K \text { is the length of the karstic segment } \\
\text { (karstic zone including vuggy, cavity, core loss, and other karstic } \\
\text { phenomena) }\end{array}$ \\
\hline
\end{tabular}

TABLE 2: Angle intervals and ratings of the factor for each interval [38].

\begin{tabular}{lccc}
\hline $\begin{array}{l}\text { Angle interval } \\
\text { (between joint } \\
\text { and borehole) }\end{array}$ & $\frac{1}{\sin \alpha}$ & $\begin{array}{c}\text { Chosen rating of } \\
\text { the factor } f_{i} \text { for } \\
\text { RQD }\end{array}$ & $\begin{array}{c}\text { Chosen rating of } \\
\text { the factor } f_{i} \text { for } \\
\text { RQD }_{\mathrm{I}}\end{array}$ \\
\hline$>60^{\circ}$ & $<1.16$ & 1 & 1.5 \\
$30^{\circ}-60^{\circ}$ & $1.16-1.99$ & 1.5 & 3.5 \\
$15^{\circ}-30^{\circ}$ & $2-3.86$ & 3.5 & 5.5 \\
$<15^{\circ}$ & $>3.86$ & 6 & 7.5 \\
\hline
\end{tabular}

maximum and minimum values of the type I and type II fracture toughness, respectively.

In Equation (7), $S_{n}$ is normalized using the $\mathrm{RQD}_{\mathrm{I}}$ value in order to characterize the structural properties of the rock formation. As mentioned above, Rickman et al. $\left(B_{2}\right)$ had previously used the dynamic elastic modulus and Poisson's ratio to characterize the rock brittleness index for a parallel contrast with the rock brittleness index $\left(B_{1}\right)$ and had proposed that the two had displayed similar trends. Therefore, in order to ensure the continuous acquisition of the brittleness index in the entire well in the study area, the $B_{n}$ in the model was characterized by $B_{2}$. The fracability index $F_{i}$ had ranged from 0 to 1 . When the fracability index of the rock formation was $F_{i}=1$, excellent fracability had been shown. However, when $F_{i}=0$, the fracability properties were considered to be extremely poor and the layer was essentially a barrier. In addition, the proportions of each influencing factor were equal in the equation, and all were $1 / 3$. In the current study, in accordance with the data results and the relevant experiences in the study area, the fracability index threshold was specified as $F_{0}$. When $F_{i}>F_{0}$, the interval was considered to have favorable fracability. The influences of the various factors on the fracability were more complicated, and their contributions were difficult to determine. However, those contributions were not found to affect the geometry of the fracability index and had only certain influences on the threshold. It was determined that when the contributions of the influencing factors were different, there must be a cutoff value which corresponded to the fracability index. Therefore, it was important to define the fracability index threshold of the rock formations based on the calculated fracability evaluation curves after setting the factor contributions.

\section{Case Application}

The main goal of the design selection prior to hydraulic fracturing is to screen out the dominant well intervals with high fracability and high hydrocarbon reserves, in order to maximize the ultimate oil and gas recovery. It was found that the fracability index model which had been established in the current study had comprehensively evaluated the fracability of the target intervals. Equations (7)-(10) were used to calculate the fracability of the shale in the Xike 2 well and plot the four-dimensional scatter of the structural index, brittleness index, fracture toughness, and fracability index, as detailed in Figure 11. The following can be seen in the figure: (1) The fracability of the rock layer with a brittleness index close to 1 was not necessarily high, since it had higher fracture toughness (small fracture toughness index) and less structural planes, as shown in the lower right corner of Figure 11. (2) The low fracture toughness (large toughness index) did not necessarily represent a favorable area for fracturing. It was observed that the brittleness index and structural complexity of the rock had affected its fracability. (3) The shale gas reservoir had high brittleness, low fracture toughness (high toughness index), and structural surface 
TABLE 3: Comparison of the four methods for calculating RQD by various researchers for XK-2 drilling cores.

\begin{tabular}{|c|c|c|c|c|c|c|}
\hline Roundtrip & $\begin{array}{l}\text { RQD } \\
\text { Deere }\end{array}$ & $\begin{array}{c}\text { RQD Pal } \\
\text { (1982) }\end{array}$ & $\begin{array}{c}\text { RQD Pal } \\
(2005)\end{array}$ & $\mathrm{RQD}_{\mathrm{c}}$ & MRQD & $\mathrm{RQD}_{\mathrm{I}}$ \\
\hline 100 & 90.5 & 99.6 & 98.33 & 6.38 & 88.67 & 88.67 \\
\hline 101 & 90.67 & 98.5 & 97.5 & 6.08 & 89.83 & 89.83 \\
\hline 102 & 95.17 & 87.5 & 89.17 & 3.88 & 87.5 & 87.5 \\
\hline 103 & 70.0 & 95.2 & 95 & 4.35 & 73.67 & 73.67 \\
\hline 104 & 73.68 & 95.2 & 95 & 4.52 & 76.83 & 76.83 \\
\hline 105 & 75.5 & 95.2 & 95 & 4.81 & 82.33 & 80.33 \\
\hline 106 & 19.83 & 100 & 100 & 3.40 & 29.5 & 29.5 \\
\hline 107 & 65.67 & 100 & 99.17 & 5.71 & 73.5 & 72.17 \\
\hline 108 & 72.83 & 99.6 & 98.33 & 5.21 & 71.17 & 69.83 \\
\hline 109 & 94.33 & 99.6 & 98.33 & 6.64 & 92.67 & 92.67 \\
\hline 110 & 71.83 & 100 & 99.17 & 6.19 & 80.17 & 80.17 \\
\hline 111 & 39.5 & 100 & 100 & 4.59 & 45.5 & 45.5 \\
\hline 112 & 40.5 & 100 & 100 & 6.92 & 39.0 & 39 \\
\hline 113 & 39.17 & 99.6 & 98.33 & 3.52 & 45.83 & 41.33 \\
\hline 114 & 76 & 85.3 & 87.5 & 3.56 & 86.17 & 86.17 \\
\hline 115 & 62.5 & 84.2 & 86.67 & 3.16 & 77.17 & 77.17 \\
\hline 116 & 73 & 85.3 & 87.5 & 3.58 & 86.5 & 86.5 \\
\hline 117 & 47.67 & 86.4 & 88.33 & 2.74 & 61 & 61 \\
\hline 118 & 68.5 & 85.3 & 87.5 & 3.33 & 79.83 & 80.33 \\
\hline 119 & 77.33 & 94.1 & 94.17 & 4.59 & 82.33 & 82.33 \\
\hline 120 & 67.83 & 95.2 & 95 & 4.56 & 77.67 & 77.67 \\
\hline 121 & 86.33 & 97.4 & 96.67 & 5.81 & 90.83 & 90.83 \\
\hline 122 & 90.33 & 99.6 & 98.33 & 6.56 & 91.33 & 91.33 \\
\hline 123 & 62.83 & 100 & 100 & 6.59 & 67.5 & 67.5 \\
\hline 124 & 76.33 & 94.1 & 94.17 & 4.56 & 81.67 & 81.67 \\
\hline 125 & 57.33 & 100 & 100 & 5.51 & 60.67 & 60.67 \\
\hline 126 & 83.67 & 100 & 99.17 & 6.60 & 85.83 & 85.83 \\
\hline 127 & 63.83 & 97.4 & 96.67 & 4.29 & 65 & 65.33 \\
\hline 128 & 84.67 & 100 & 100 & 9.41 & 80.67 & 80.67 \\
\hline 129 & 84.67 & 100 & 100 & 7.15 & 87 & 87 \\
\hline 130 & 79.67 & 100 & 100 & 6.77 & 82 & 82 \\
\hline 131 & 70.5 & 100 & 100 & 8.28 & 70.5 & 70.5 \\
\hline 132 & 58.33 & 100 & 99.17 & 4.70 & 59.33 & 59.33 \\
\hline 133 & 79.33 & 96.3 & 95.83 & 5.00 & 81.5 & 81.5 \\
\hline 134 & 70.17 & 99.6 & 98.33 & 5.29 & 72.33 & 72.33 \\
\hline
\end{tabular}

development, which indicated that the reservoir had strong fracability characteristics.

In this research study, based on the core records and conventional logging data, the proposed fracturing index model had been successfully applied in the Xike 2 well of the Wufeng-Longmaxi Formation in northern Guiyang, as detailed in Figure 12. The following conclusions were reached in this study from the experimental results:

(1) For the well in the study area, it was ascertained that 0.405 could be selected as the cutoff value of the fracability index in accordance with the fracability index curve, relevant data of adjacent areas, and expert

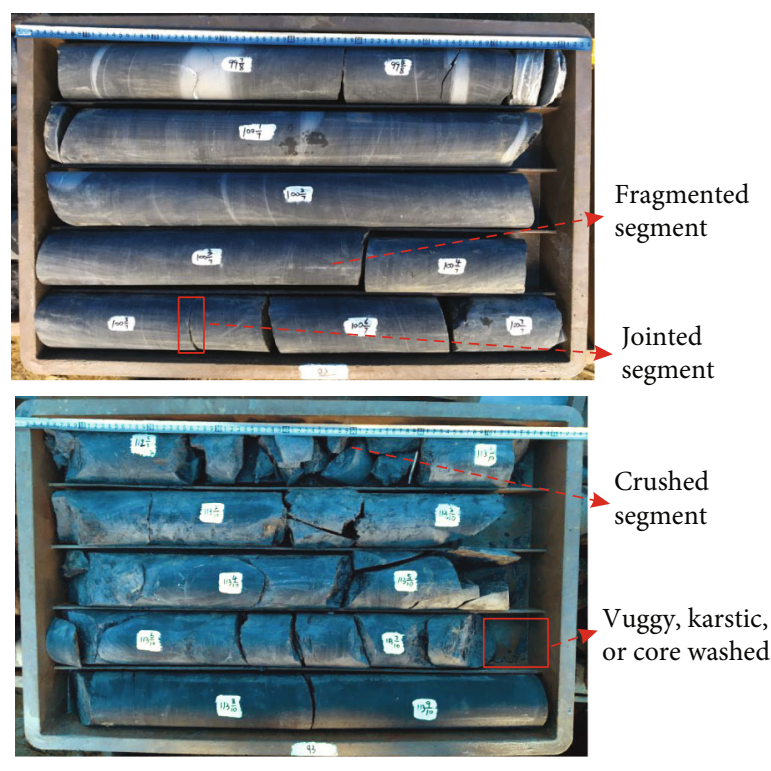

Figure 8: Presentation of different drilling cores.

experience. It was confirmed that when $F_{i}>0.405$, the strata could be considered a candidate for fracturing. Otherwise, it was considered to be a barrier for fracturing. After the screening and classification processes were completed, there were seven favorable fracturing intervals identified. In line 9 of Figure 12, the yellow section indicates the layers with potentially good fracability (Fra1 to Fra7), and the green section in line 9 of Figure 12 indicates the barrier layers (Bar1 to Bar7)

(2) It was found that Bar7 had a high brittleness index. However, it had fewer internal fracturing surfaces and poor fracability potential. Therefore, it was considered to be a barrier layer. Fra1, Fra2, Bar6, and Bar7 also exhibited different brittleness indexes and fracability trends. Therefore, it was found that $F_{i}$ did not always monotonously increase with the increases in brittleness. It was considered to be inaccurate to use only the brittleness index to characterize the fracability in this study. The reasons for this were mainly related to the differences in the trends of the fracture toughness and rock structures

(3) In the study area, the Bar1 and Bar2 layers were considered to be effective barriers to fracability. The identifications of these effective barriers had been mainly dependent on the differences in $F_{i}$ and the thicknesses of the adjacent layers. It was observed that Bar6 and Bar7 had also had poor fracability potential. However, due to their small thicknesses, which may not have prevented the extensions of hydraulic cracks, they were considered to be ineffective barriers. Similarly, Fra3 and Fra4 had displayed good fracability potential. However, due to their small thicknesses and the fact that the cracks could not be effectively expanded due to other barrier hindrances, they were categorized as ineffective 


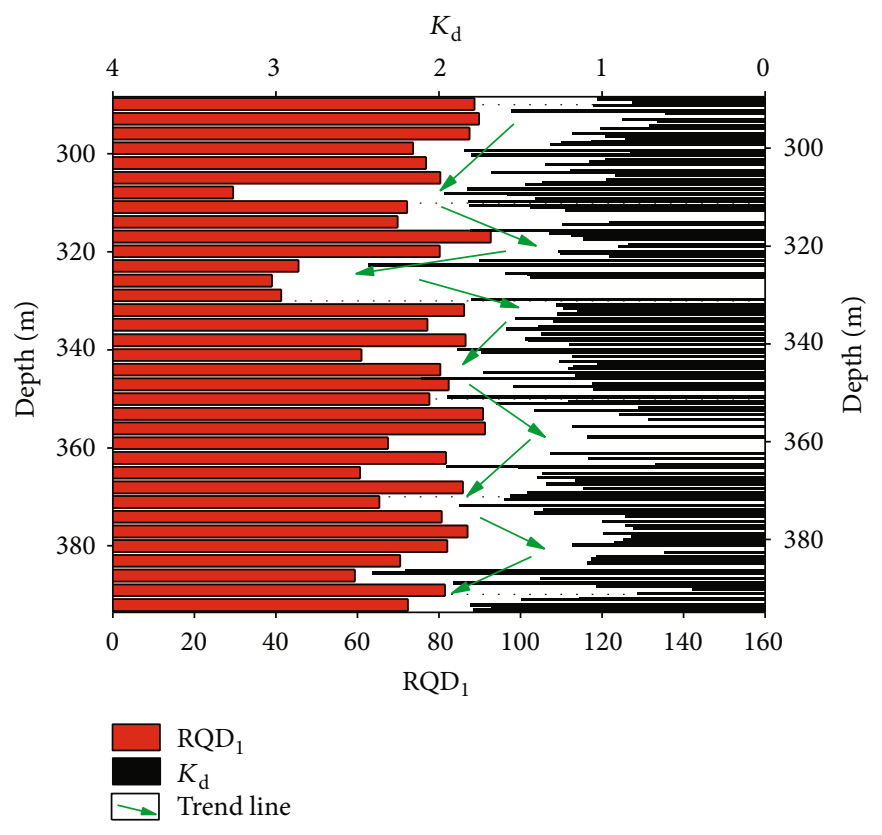

Figure 9: The bar graph of $\mathrm{RQD}_{\mathrm{I}}$ and $K_{\mathrm{d}}$.

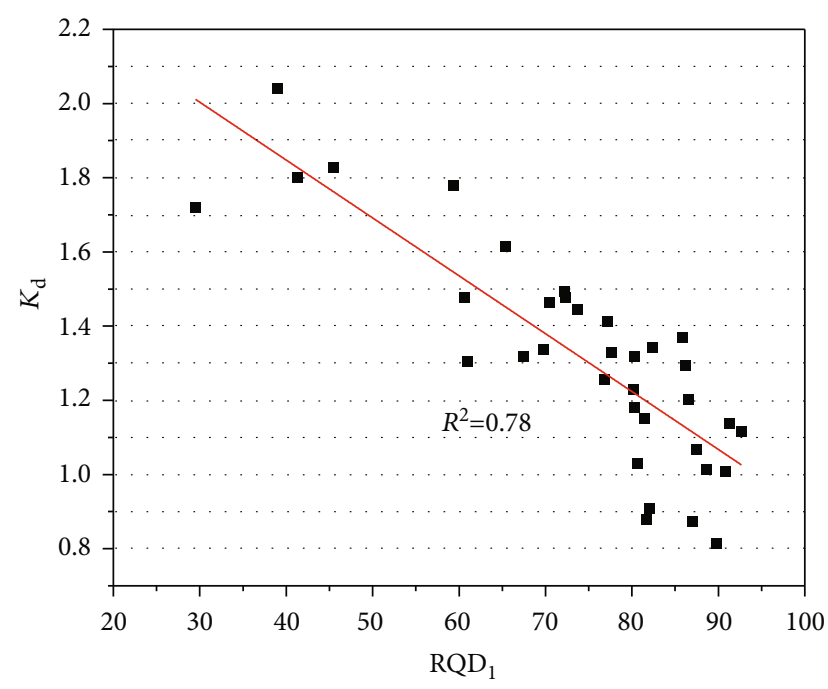

Figure 10: The image of relationship between $\mathrm{RQD}_{\mathrm{I}}$ and $K_{\mathrm{d}}$.

fracturing layers. In summary, this study determined that Fra1, Fra2, Fra5, Fra6, and Fra7, as well as Bar6 and Bar7, were effective fractured intervals. The others were considered to be effective barrier intervals, as detailed in lines 10 and 11 of Figure 12

The fracability evaluation method of combining brittleness and fracture energy proposed by Jin has been successfully applied in the hydraulic fracturing design of the North American shale gas field [33]. The index is shown in

$$
F_{\text {Jin }}=\frac{B_{n}+K_{\mathrm{IC}-n}}{2},
$$

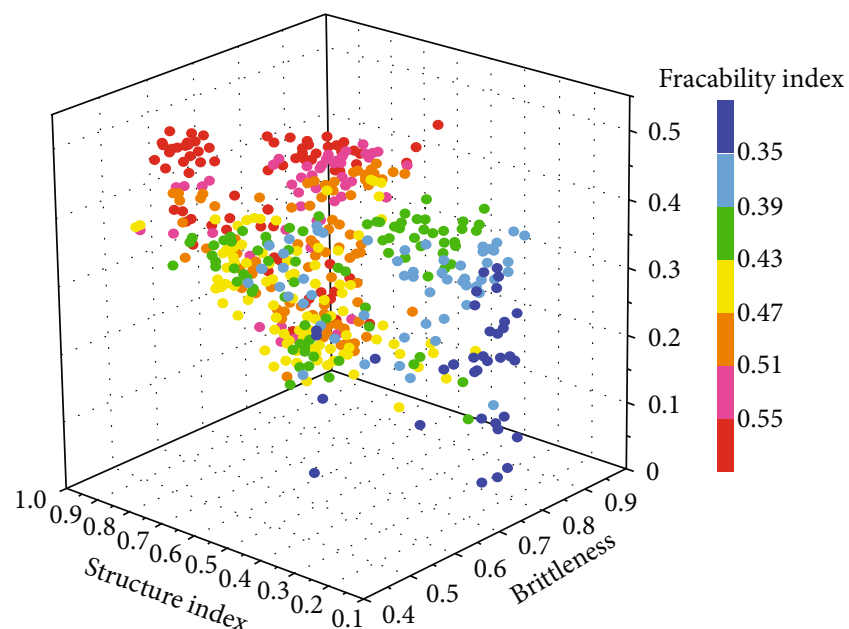

FIGURE 11: Fracability index variation of the shale gas reservoir.

where $B_{n}$ is the normalized brittleness index and $K_{\mathrm{IC}-n}$ is the normalized fracture toughness.

In order to verify the accuracy of the model described in this paper, the index of Jin is calculated. According to Figure 13, the two curves have high similarity, with high fracability at the depth of $370-395 \mathrm{~m}$. Our index is higher at the depths of $305-310 \mathrm{~m}$ and $320-330 \mathrm{~m}$, but Jin's fracability index is lower. This is because Jin's index is mainly based on the mechanical performance and mineral components of reservoirs and does not consider the impact of rock structure.

In summary, the proposed fracability index model successfully provided a new tool for effective barrier identification, favorable fracturing interval screening, drilling, and perforation optimization. 


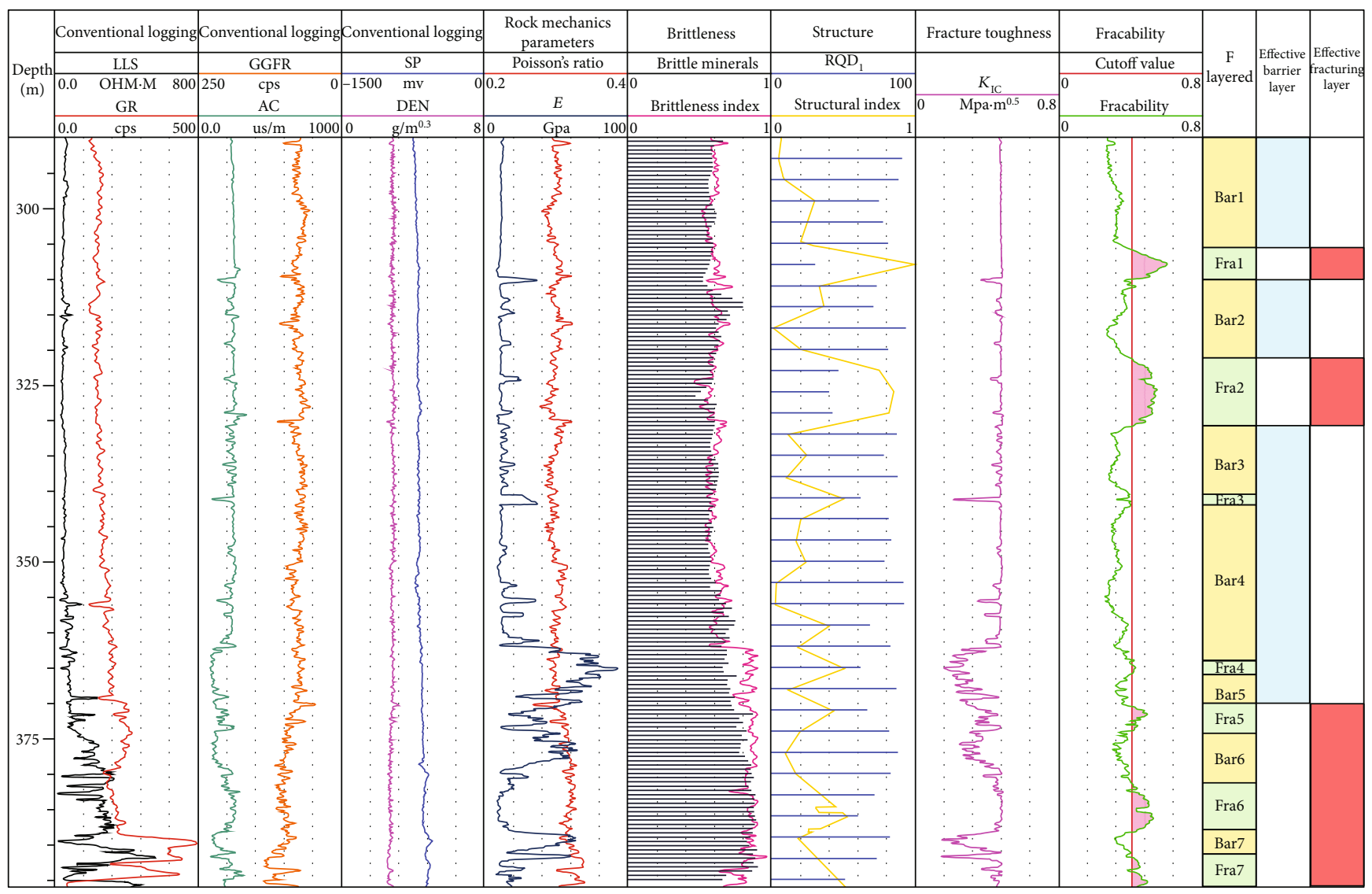

FIGURE 12: Screening hydraulic fracturing candidates with a fracability index (Xike 2).

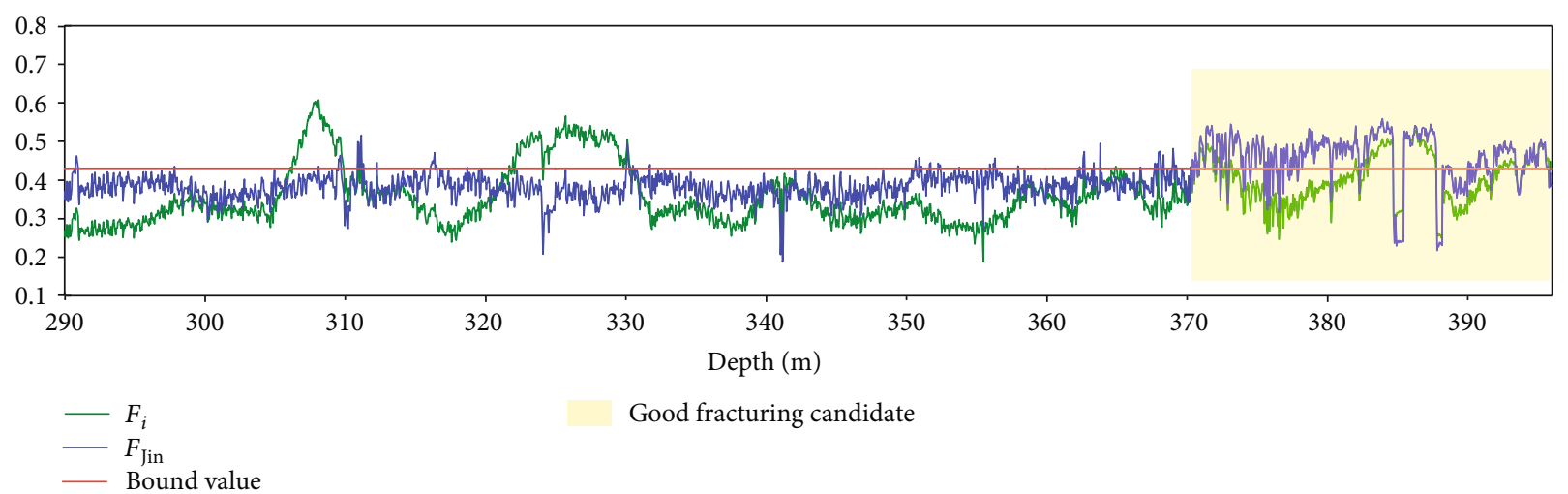

FIGURE 13: Comparison with Jin's fracability (where $F_{i}$ is the fracability index defined in this paper and $F_{\text {Jin }}$ is the fracability index defined by Jin).

In this paper, we strictly follow the relevant test regulations and procedures, thereby reducing the uncertainty of the results. For the calculation of $B_{n}, K_{n}$, and $S_{n}$, the errors are acceptable for engineering applications. Due to the difficulty of collecting cores, the verification of cores is not performed in this paper. At present, field hydraulic fracturing tests are beginning to be performed, which are what we are studying now and will elaborate in detail in our future papers.

\section{Conclusions}

In this research study, a new method was proposed for describing the fracture properties of unconventional hydrocarbon reservoirs based on the characteristics of the rock structures, reservoir brittleness, and fracture toughness.

(1) The structural characteristics were found to be complicated by many parameters. Therefore, the model 
was simplified in this study, and RQD was used for the rock structure characterization. A comparative analysis was performed, by means of five commonly used RQD calculation methods. These included Deere's RQD, which did not consider the influences of joints; Palmstrom's RQD, which did not consider the existence of weak areas; and MRQD, which did not consider the directions of the joints. It was found that the results of the three aforementioned methods were inconsistent with the actual situation. However, the results obtained using the $\mathrm{RQD}_{\mathrm{I}}$ method more accurately described the integrity of the core. Meanwhile, the RQD and the bedding line density were compared in order to show a good correlation. In summary, it was confirmed that the $\mathrm{RQD}_{\mathrm{I}}$ can be used to characterize rock structures. The larger the $\mathrm{RQD}_{\mathrm{I}}$ was, the more complete the rock structure would be. Otherwise, the rock would be easily fractured. It was found that the proposed method was easy to operate and implement

(2) A fracability evaluation model of the shale based on rock brittleness, structural characteristics, and fracture toughness was established in this study to define the fracability index. The fracability index ranged between 0 and 1 . When $F_{i}$ was close to 1 , the rock of that interval was considered to have good fracture properties. However, when it was close to 0 , it was considered to be a barrier. The three factors had a comprehensive impact on the fracability index, while the layers with high brittleness indexes did not necessarily have good fracability. This may have been due to their large fracture toughness and complete structures, and the other factors had similar theories

(3) In accordance with the on-site cataloging and logging data, the proposed fracturing index model had been successfully applied in the Xike 2 well of the Wufeng-Longmaxi Formation. Six favorable fracturing intervals had been selected, which were mainly distributed in the Wufeng Formation and the upper and lower sections of the Longmaxi Formation. Therefore, the proposed method had provided a basis for subsequent fracturing implementations and perforation optimization and could potentially improve the ultimate recovery of unconventional natural gas

\section{Data Availability}

The data used to support the findings of this study are available from the corresponding author upon request.

\section{Conflicts of Interest}

All of the authors declare that they do not have any conflict of interest.

\section{Acknowledgments}

This research is financially supported by the Strategic Priority Research Program of the Chinese Academy of Sciences (grant no. XDB10030104).

\section{References}

[1] D. M. Jarvie, R. J. Hill, T. E. Ruble, and R. M. Pollastro, "Unconventional shale-gas systems: the Mississippian Barnett Shale of North-Central Texas as one model for thermogenic shale-gas assessment," AAPG Bulletin, vol. 91, no. 4, pp. 475-499, 2007.

[2] R. Rickman, M. J. Mullen, J. E. Petre, W. V. Grieser, and D. Kundert, "A practical use of shale petrophysics for stimulation design optimization: all shale plays are not clones of the Barnett Shale," in SPE Annual Technical Conference and Exhibition, Denver, CO, USA, September 2008.

[3] F. P. Wang and J. F. W. Gale, "Screening criteria for shale-gas systems," Gulf Coast Association of Geological Societies Transactions, vol. 59, pp. 779-793, 2009.

[4] K. K. Chong, W. V. Grieser, A. Passman, H. C. Tamayo, N. Modeland, and B. E. Burke, "A completions guide book to shale-play development: a review of successful approaches towards shale-play stimulation in the last two decade," in Proceedings of Canadian Unconventional Resources and International Petroleum Conference, Galary, Alberta, Canada, January 2010.

[5] X. Jin, S. N. Shah, J. C. Roegiers, and B. Zhang, "Fracability evaluation in shale reservoirs-an integrated petrophysics and geomechanics approach," in SPE Annual Technical Conference and Exhibition, The Woodlands, TX, USA, February 2014.

[6] V. Hucka and B. Das, "Brittleness determination of rocks by different methods," International Journal of Rock Mechanics and Mining Sciences \& Geomechanics Abstracts, vol. 11, no. 10, pp. 389-392, 1974.

[7] S. P. Singh, "Brittleness and the mechanical winning of coal," Mining Science and Technology, vol. 3, no. 3, pp. 173-180, 1986.

[8] M. J. Daniel, J. H. Ronald, and E. R. Tim, “A comparative study of the Mississippian Barnett Shale, Fort Worth Basin, and Devonian Marcellus Shale, Appalachian Basin," AAPG Bulletin, vol. 91, no. 4, pp. 475-499, 2011.

[9] M. Bai, "Why are brittleness and fracability not equivalent in designing hydraulic fracturing in tight shale gas reservoirs," Petroleum, vol. 2, no. 1, pp. 1-19, 2016.

[10] D. P. Kundert and M. J. Mullen, "Proper evaluation of shale gas reservoirs leads to a more effective hydraulic-fracture stimulation," in SPE Rocky Mountain Petroleum Technology Conference, Denver, CO, USA, April 2009.

[11] R. M. Slatt and Y. Abousleiman, "Multi-scale, brittle-ductile couplets in unconventional gas shales: merging sequence stratigraphy and geomechanics," in AAPG Annual Convention and Exhibition, Houston, TX, USA, April 2011.

[12] H. T. Alassi, R. M. Holt, O. M. Nes, and S. Pradhan, "Realistic geomechanical modeling of hydraulic fracturing in fractured reservoir rock," in Canadian Unconventional Resources Conference, Calgary, AL, Canada, January 2011.

[13] M. Enderlin, H. Alsleben, and J. A. Beyer, "Predicting fracability in shale reservoirs," in AAPG Annual Convention and Exhibition, Houston, TX, USA, April 2011. 
[14] Y. Tang, Y. Xing, L. Z. Li, B. H. Zhang, and S. X. Jiang, "Influence factors and evaluation methods of the gas shale fracability," Earth Science Frontiers, vol. 19, no. 5, pp. 356-363, 2012.

[15] J. Yuan, J. Deng, D. Zhang et al., "Fracability evaluation of shale-gas reservoirs," Acta Petrolei Sinica, vol. 34, no. 3, pp. 523-527, 2013.

[16] T. Guo, S. Zhang, H. Ge, X. Wang, X. Lei, and B. Xiao, “A new method for evaluation of fracture network formation capacity of rock," Fuel, vol. 140, pp. 778-787, 2015.

[17] M. J. Mayerhofer, E. Lolon, N. R. Warpinski, C. L. Cipolla, D. W. Walser, and C. M. Rightmire, "What is stimulated rock volume?" in SPE Shale Gas Production Conference, Fort Worth, TX, USA, November 2008.

[18] N. R. Warpinski, M. Mayerhofer, K. Agarwal, and J. Du, "Hydraulic-fracture geomechanics and microseismic-source mechanisms," SPE Journal, vol. 18, no. 4, pp. 766-780, 2013.

[19] H. Zhu, L. Tao, D. Liu, Q. Liu, and X. Jin, "Fracability estimation for Longmaxi shale: coupled brittleness, stress-strain and fracture," Arabian Journal for Science and Engineering, vol. 43, no. 11, pp. 6639-6652, 2018.

[20] K. D. Mahrer, "A review and perspective on far-field hydraulic fracture geometry studies," Journal of Petroleum Science and Engineering, vol. 24, no. 1, pp. 13-28, 1999.

[21] T. L. Blanton, "An experimental study of interaction between hydraulically induced and pre-existing fractures," in SPE Unconventional Gas Recovery Symposium, Pittsburgh, PA, USA, May 1982.

[22] T. L. Blanton, "Propagation of hydraulically and dynamically induced fractures in naturally fractured reservoirs," in SPE Unconventional Gas Technology Symposium, Louisville, KY, USA, May 1986.

[23] S. Heng, C. H. Yang, Y. J. Zeng, Y. T. Guo, L. Wang, and Z. K. Hou, "Experimental study on hydraulic fracture geometry of shale," Chinese Journal of Geotechnical Engineering, vol. 36, no. 7, pp. 1243-1251, 2014.

[24] S. Heng, C. H. Yang, Y. T. Guo, C. Y. Wang, and L. Wang, "Influence of bedding planes on hydraulic fracture propagation in shale formations," Chinese Journal of Rock Mechanics and Engineering, vol. 34, no. 2, pp. 228-237, 2015.

[25] C. Jia, J. Chen, Y. Guo, C. H. Yang, J. B. Xu, and L. Wang, "Research on mechanical behaviors and failure models of layer shale," Rock and Soil Mechanics, vol. 34, pp. 57-61, 2013.

[26] D. Xu, R. Hu, W. Gao, and J. Xia, "Effects of laminated structure on hydraulic fracture propagation in shale," Petraleum Exploration and Development, vol. 42, no. 4, pp. 573-579, 2015.

[27] L. Xing, Y. Xi, Z. Jiehui, and S. Honglin, "Reservoir forming conditions and favorable exploration zones of shale gas in the Weixin Sag, Dianqianbei Depression," Petroleum Exploration and Development, vol. 38, no. 6, pp. 693-699, 2011.

[28] H.-Y. Zhu, L. Tao, Q.-Y. Liu, Z.-D. Lei, S. Jiang, and J. D. McLennan, "Fracture characteristics and change of permeability under the influence of natural fractures: experimental study of Wufeng-Longmaxi shale," SPE Reservoir Evaluation \& Engineering, vol. 21, no. 2, pp. 225-237, 2017.

[29] Y. Wang, X. Li, Y. F. Wu, B. Yuxing, L. I. Shouding, and H. E. Jianming, "Research on relationship between crack initiation stress level and brittleness indices for brittle rocks," Chinese Journal of Rock Mechanics and Engineering, vol. 33, no. 2, pp. 264-275, 2014.
[30] Q. Li, M. Chen, Y. Jin, F. P. Wang, B. Hou, and B. Zhang, "Indoor evaluation method for shale brittleness and improvement," Chinese Journal of Rock Mechanics and Engineering, vol. 31, no. 8, pp. 1680-1685, 2012.

[31] D. Zhang, P. G. Ranjith, and M. S. A. Perera, “The brittleness indices used in rock mechanics and their application in shale hydraulic fracturing: a review," Journal of Petroleum Science and Engineering, vol. 143, pp. 158-170, 2016.

[32] X. Jin, S. N. Shah, J.-C. Roegiers, and B. Zhang, "An integrated petrophysics and geomechanics approach for fracability evaluation in shale reservoirs," SPE Journal, vol. 20, no. 3, pp. 518526, 2015.

[33] Z. Chen, C. Mian, and J. Yan, "Experimental study on the relationship between rock fracture toughness and acoustic velocity," Oil Drillinge Production Technology, vol. 19, no. 5, pp. 56-75, 1997.

[34] J. Yan and C. Mian, "Determination of fracture toughness for deep well rock geophysical logging data," Chinese Journal of Rock Mechanics and Engineering, vol. 20, no. 4, pp. 454-456, 2001.

[35] Y. Jin, J. Yuan, M. Chen, K. P. Chen, Y. Lu, and H. Wang, "Determination of rock fracture toughness ${ }_{\mathrm{K} \text { IIC }}$ and its relationship with tensile strength," Rock Mechanics and Rock Engineering, vol. 44, no. 5, pp. 621-627, 2011.

[36] L. Yishan and J. YeQuan, Rock Mechanics and Petroleum Engineering, Petroleum Industry Press, 2006.

[37] D. U. Deere and D. W. Deere, "The rock quality designation (RQD) index in practice," in Rock Classification System for Engineering Purpose, L. Kirkaldie, Ed., pp. 91-101, ASTM International, West Conshohocken, PA, USA, 1988.

[38] A. Azimian, "A new method for improving the RQD determination of rock core in borehole," Rock Mechanics and Rock Engineering, vol. 49, no. 4, pp. 1559-1566, 2016.

[39] A. Palmstrom, "Measurements of and correlations between block size and rock quality designation (RQD)," Tunnelling and Underground Space Technology, vol. 20, no. 4, pp. 362377, 2005.

[40] L. Li, S. Ouellet, and M. Aubertin, "An improved definition of rock quality designation, RQDc," in ROCKENG09: Proceedings of the 3rd CANUS Rock Mechanics Symposium, Toronto, May 2009.

[41] G. Ji, K. Li, G. Zhang, S. Li, and L. Zhang, “An assessment method for shale fracability based on fractal theory and fracture toughness," Engineering Fracture Mechanics, vol. 211, pp. 282-290, 2019. 

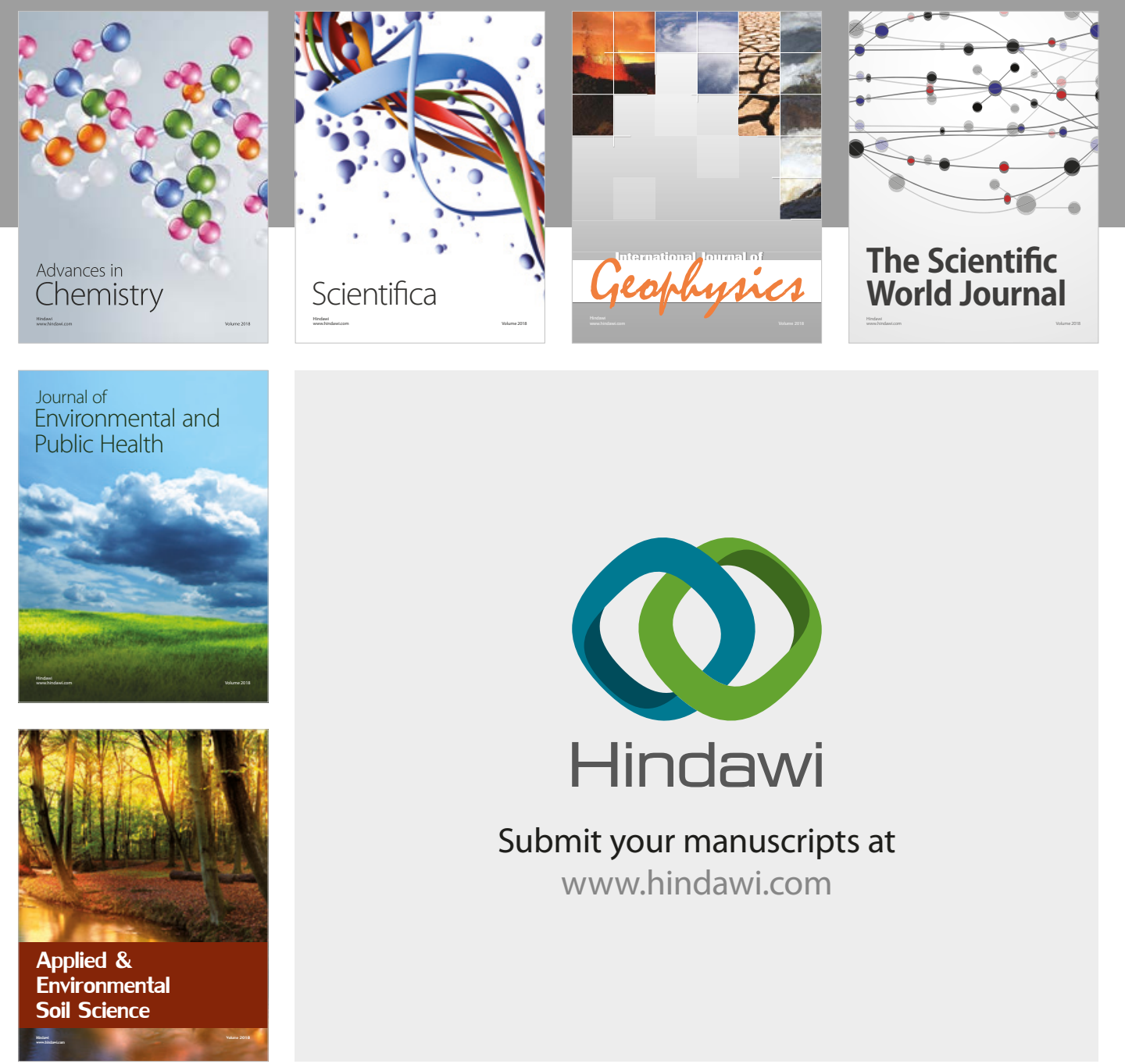

The Scientific

\section{World Journal}
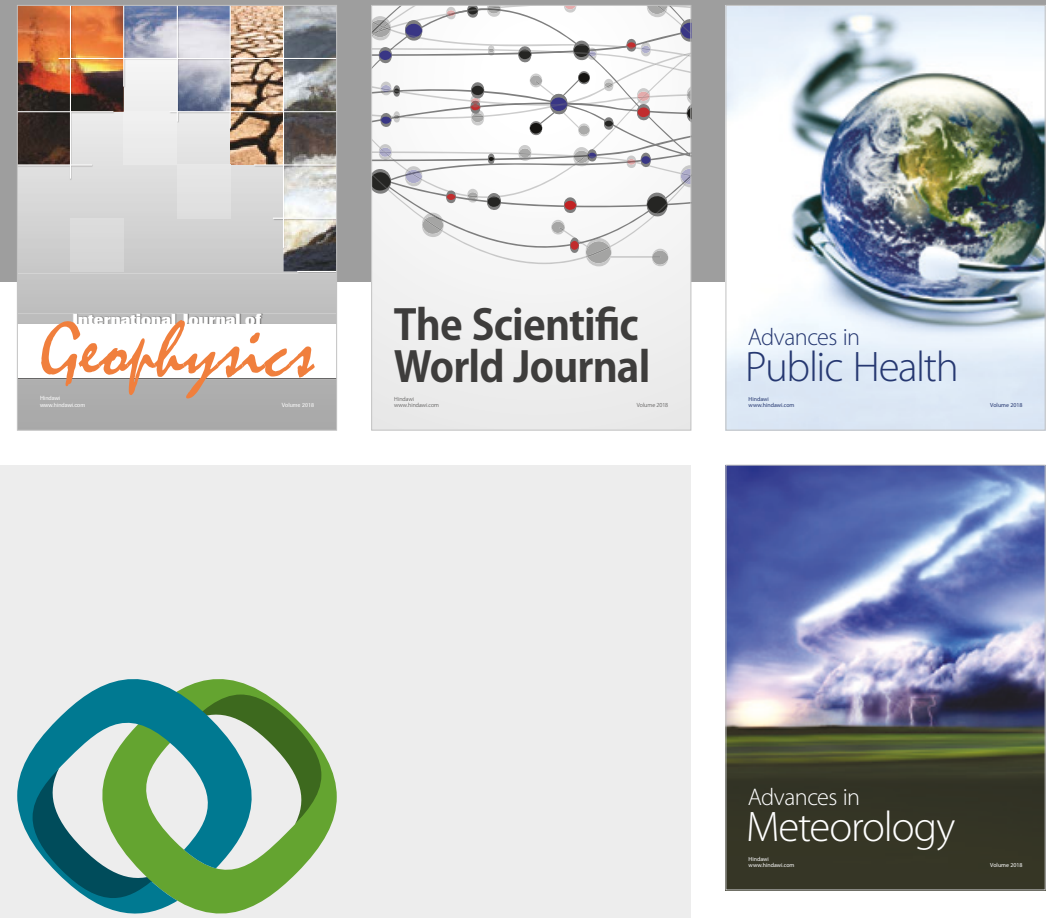

Advan

Public Health

\section{Hindawi}

Submit your manuscripts at

www.hindawi.com
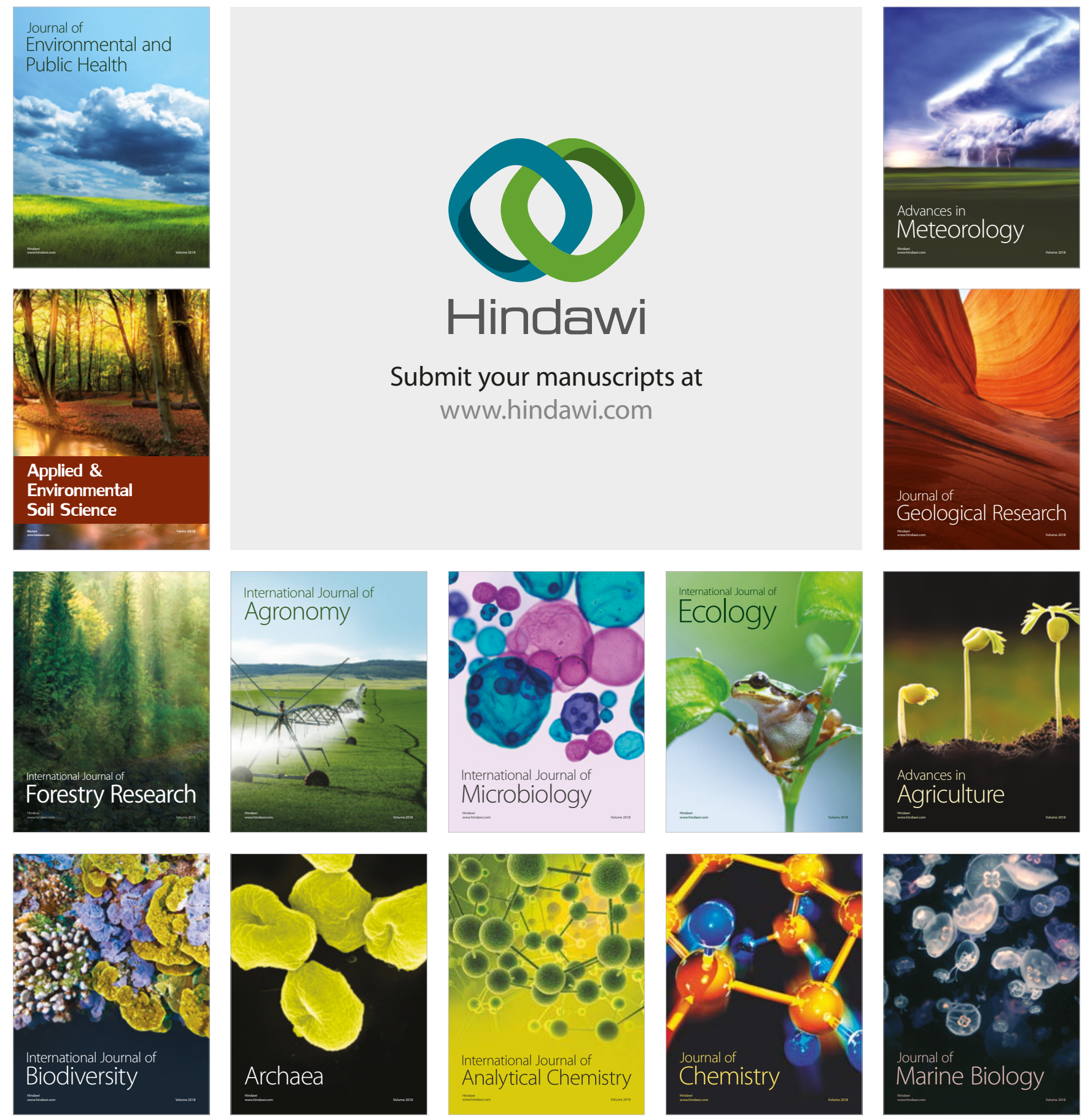